\title{
Los "compromisos" de la dominación. Una aproximación al Behemoth de Franz Neumann
}

\author{
The "commitments" of domination. \\ An approach to Franz Neumann's Behemoth
}

Francisco Abrit

\begin{abstract}
Resumen: en el presente artículo nos proponemos explicitar cuáles son las principales características que Franz Neumann -autor del círculo "externo" de la primera Teoría Crítica- le atribuye a la dominación socio-política. Para abordar esta cuestión es necesario reseñar algunas de las principales tesis de su clásico libro sobre el nacional-socialismo titulado Behemoth, prestando especial atención a su análisis relativo a la destrucción de la racionalidad jurídica. Nos interesa, puntualmente, responder a la siguiente pregunta: ¿hay en su propuesta una concepción de dominación que presuponga, además de coerción, consentimiento y participación de los grupos dominados? Para poder dar cuenta de las distintas aristas que detenta este interrogante, consideramos necesario retomar los aportes que hace Axel Honneth uno de los tantos teóricos contemporáneos que instan a recuperar los estudios de Neumann- en su libro Crítica del poder, donde hace mención a la existencia de "relaciones bilaterales de dominio". Aquí veremos que Neumann ofrece precisiones para responder al problema de la "dominación bilateral" -así lo llamaremos-, pero con limitaciones nada desdeñables. Limitaciones que, y ésta es una sugerencia que haremos al final del artículo, podrían sortearse a partir de un diálogo más abarcador que involucre a otros miembros del círculo "externo".
\end{abstract}

Palabras clave: Franz Neumann, Axel Honneth, dominación bilateral, consentimiento, participación

* Doctor en Filosofía por la Universidad Nacional del Córdoba (Argentina). Licenciado en Comunicación Social y en Filosofía por la misma universidad. Actualmente es becario posdoctoral de Consejo Nacional de Investigaciones Cinetíficas y Técnicas (CONICET). Su tesis doctoral se tituló "Repensar la dominación. Axel Honneth y el legado de la Teoría Crítica", siendo el proyecto postdoctoral una continuación y profundización de ese trabajo. Dirección electrónica: franciscoabril_2@hotmail.com 


\begin{abstract}
: in this paper we will try to make explicit what are the main features that Franz Neumann -a member of the "outer" circle of the first Critical Theoryattributed to the socio-political domination. To approach this issue, it is necessary to review some of the central theses of his classic book on national-socialism entitled Behemoth, paying special attention to his analysis on the destruction of legal rationality. We are particularly interested in answering the following question: in his proposal, is there a conception of domination that refers not only to coercion, but also to the consent and participation of dominated groups? In order to explain the different aspects of this question, we consider it necessary to recover the contributions made by Axel Honneth -one of the many contemporary theorists who seek to revalue Neumann's work - in his book The Critique of Power. In that book Honneth mentions the existence of "bilateral relations of domination". Here we will see that Neumann offers precisions to answer the problem of the so-called "bilateral domination", but with important constraints. Constraints that could be overcome through a more comprehensive dialogue involving other members of the "outer" circle. This is a suggestion that we will make at the end of the article.
\end{abstract}

Keywords: Franz Neumann, Axel Honneth, bilateral domination, consent, participation

El legado de la Teoría Crítica está atravesado por campos de fuerza, por conflictos y escisiones internas. El Institut für Soz̧ialforschung no constituyó -ni constituye aún- una perspectiva teórica homogénea. Por el contrario, hubo enfoques contrapuestos respecto a temas centrales en política, economía y cultura. Frente a los procesos de ascenso y consolidación del poder nacional-socialista en Alemania, se suscitaron discusiones entre sus miembros que resultaron claves y a la vez disruptivas. Discusiones en torno al carácter de la dominación totalitaria, a la interpretación del rol de la incipiente industria cultural, y al análisis de la represión y el control psicológico de las masas.

Algunos historiadores ${ }^{1}$ afirman que, durante los años cuarenta, existió en el seno de la Teoría Crítica una división entre un círculo "interno" y uno "externo". Un círculo de intelectuales allegados a Max Horkheimer, entre los

${ }^{1}$ Cfr. Wiggershaus, Rolf, La Escuela de Francfort, Buenos Aires, FCE, 2010, p. 355. Véase también el artículo de Pérez, Alberto, "La teoría crítica entre el centro y los márgenes del Instituto de Investigación Social”, Pensar, 2, 2007. 
cuales estaban Friedrich Pollock, Theodor Adorno y Herbert Marcuse. Y un círculo "externo" de autores más o menos marginales respecto al núcleo duro de lo que equívocamente se dio en conocer como Escuela de Frankfurt: Franz Neumann, Otto Kirchheimer, Walter Benjamin y Erich Fromm.

En el artículo "Teoría Crítica"2 [1987], una suerte de síntesis y a la vez prolongación de su libro Crítica del poder [1985], Axel Honneth -actual director del Institut- propuso una defensa explícita del círculo externo. Según él, "los instrumentos socio-teóricos que hubieran permitido alcanzar los objetivos de Horkheimer sólo estaban presentes en las obras de aquellos autores que ocupaban una posición marginal, "periférica»". ${ }^{3}$ Dicho en otras palabras, ellos lograron eludir muchas de las dificultades que caracterizaron al círculo interno de la Teoría Crítica. Por este motivo, sostiene, es preciso recuperar y continuar sus investigaciones. ${ }^{4}$

En línea de continuidad con la lectura de Honneth -a la que volveremos una y otra vez a lo largo de este escrito-, consideramos de particular relevancia el análisis que Franz Neumann ${ }^{5}$ hizo de la dominación

${ }^{2}$ Honneth, Axel, "Teoría Crítica", en Giddens, Anthony y Turner, Jonathan (comps.) La teoría social, hoy, Madrid, Alianza, 1990, pp. 445-488.

${ }^{3}$ Ibidem, p. 446.

${ }^{4}$ William Scheuerman le da la razón: "Honneth está, ciertamente, en lo correcto al sugerir que necesitamos desarrollar una renovada apreciación de ambos autores [Neumann y Kirchheimer], si perseguimos una comprensión más adecuada de las posibilidades fallidas y perdidas de la Escuela de Frankfurt" (Scheuerman, William, Between the norm and the exception. The Frankfurt School and the rule of law, Cambridge, The MIT Press, 1994, p. 154, la traducción es nuestra).

${ }^{5}$ Franz Neumann (1900-1954) fue un abogado y politólogo alemán que estudió, durante su exilio en Inglaterra, con Harold Laski y Karl Mannheim. En 1936 se unió al Instituto de Investigación Social dirigido por Horkheimer, inicialmente como asesor legal y luego como colaborador en los diferentes programas de investigación. En los 40 , siguió trabajando en el Instituto, pero cada vez con menos intensidad y con muchas diferencias con algunos de sus miembros más importantes. Trabajó también para el gobierno norteamericano durante los años de la Segunda Guerra Mundial y fue profesor de la Universidad de Nueva York, desde 1949 hasta su muerte, debida a un accidente de auto, en 1954. Para un recorrido por su trayectoria personal e intelectual, véase la entrada de David Kettler a la International Encyclopedia of the Social 
política y económica del nazismo alemán. Su libro Behemoth. Pensamiento y acción en el nacional-socialismo, ${ }^{6}$ publicado en el año 1942, es ya un clásico de la historiografía sobre la Segunda Guerra Mundial. Representa una suerte de anatomía de la estructura política, económica e ideológica del nazismo. Una visión sobre la organización de un régimen que, paradójicamente, apostó a la destrucción del orden político y de su racionalidad.

Muchas de las potencialidades de la propuesta de Neumann radican en la manera en que define los procesos socio-históricos, no ya como atravesados por mecanismos autónomos de dominación -tal y como los comprendieron, por ejemplo, Adorno y Horkheimer-, sino como instancias abiertas y conflictivas. ${ }^{7}$ Podemos encontrar, también, relevantes diferenciaciones, por ejemplo, entre totalitarismo, Estado autoritario y Estado democrático. ${ }^{8} \mathrm{Y}$, por último, en su reflexión hay elementos que permitirían elaborar un concepto complejo de dominación, uno que no suscriba a visiones instrumentales o unilaterales. ${ }^{9}$

Ante las potencialidades de su propuesta, nos proponemos explicitar cuáles son las principales características que Neumann le atribuye a la dominación social y política. Para abordar esta cuestión, es necesario reseñar

Science (2nd. Edition), editada por William Darity, The Gale Group, Detroit, 2008, pp. 481-483.

${ }^{6}$ Este libro tuvo una relevancia central en el trabajo que Neumann, Kirchheimer y Marcuse llevaron a cabo durante la guerra en la Oficina de Servicios Estratégicos norteamericana. En palabras de Barry M. Kätz: “(...) el monumental estudio de Franz Neumann sobre el Behemoth nacionalsocialista, completado poco antes de ingresar al gobierno, informó gran parte de la investigación en curso de la sección (que a su vez completó muchas de sus omisiones y contribuyó al extenso apéndice de la segunda edición que apareció en el verano de 1944)" (Kätz, Barry, "The Criticism of Arms: The Frankfurt School Goes to War", en The Journal of Modern History, 59, 3, 1987, pp. 449-450, la traducción es nuestra). Sobre el tema, también puede consultarse el libro Secret Reports on Nazi Germany. The Frankfurt School Contribution to the War Effort, con informes de Franz Neumann, Herbert Marcuse y Otto Kirchheimer. El libro fue editado por Raffaele Laudani y tiene un estudio introductorio de Raymond Geuss, New Jersey, Princeton University Press, 2013.

${ }^{7}$ Honneth, A., "Teoría Crítica", p. 465

8 AA.VV, Voces de la filosofia francesa contemporánea, Buenos Aires, Colihue, 2005, p. 67.

${ }^{9}$ Honneth, A., "Teoría Crítica”, p. 467 
algunas de las principales tesis del Behemoth (1) y exponer con mayor detenimiento su análisis de la destrucción de la racionalidad jurídica (2). Asimismo, nos interesa abordar el siguiente problema: chay en la propuesta de Neumann una concepción de dominación que presuponga, además de imposición abierta y violencia, consentimiento y participación no sólo de los grupos dominantes, sino también de los dominados? Para explicitar esta concepción retomaremos los aportes de Honneth en su libro Crítica del poder, donde hace mención a las "relaciones bilaterales de dominio". ${ }^{10}$ Aquí veremos que, en efecto, Neumann ofrece precisiones para responder al problema de la "dominación bilateral" -así lo llamaremos- (3). Veremos que estas precisiones no están exentas de ciertas limitaciones, limitaciones que podrían sortearse -lo sugerimos como una línea abierta para futuros escritos- a partir de un diálogo con otro autor del círculo externo: Erich Fromm.

\section{Tesis principales}

El nombre Behemoth refiere a una criatura de la mitología judía que representa el gobierno del caos sobre la tierra y se opone a Leviatán que habita las aguas. Según la mitología, ambas criaturas terminarían, al final de los tiempos, luchando y destruyéndose entre sí. ${ }^{11}$ Asimismo, hay una alusión al libro de Hobbes en el que se describía la guerra civil en Inglaterra durante el siglo XVII y cómo se erigió, a partir de ella, un Estado aberrante carente de leyes. Aquí también hay una diferencia entre Behemoth y Leviatán. En este último caso, el Estado persevera y supone un mínimo de racionalidad y legalidad. ${ }^{12}$

Con esta doble referencia se deja entrever la tesis del libro de Neumann: el nacional-socialismo significó el avance de la irracionalidad y de la destrucción del Estado. Dicho con otras palabras: su tendencia inherente

${ }^{10}$ Honneth, Axel, Crítica del poder. Fases en la reflexión de una Teoría Crítica de la Sociedad, Madrid, Mínimo Tránsito, 2009, p. 101.

${ }^{11}$ Neumann, Franz, Behemoth. Pensamiento y acción en el nacional-socialismo, México, FCE, 2005, p. 11.

${ }^{12}$ Ibidem, p. 507. 
fue la de convertirse en un no-Estado. ${ }^{13}$ A lo sumo, consistió en una gestión del caos en virtud del incremento del poder político y económico. Esto quiere decir, entre otras cosas, que las relaciones entre la clase dirigente y la clase dirigida se volvieron cada vez más inmediatas. En el período anterior, mediaban las leyes y el control jurídico y parlamentario sobre el accionar del poder soberano y coercitivo; con el nacional-socialismo, se estableció una relación de abierta opresión.

Neumann es muy preciso a la hora de explicitar quiénes conformaron la clase dirigente alemana y quiénes la dirigida. En Alemania el poder se repartió en virtud de un pacto o compromiso entre cuatro grandes grupos como lo llama P. Hayes, un "quadrunvirato"14-: el partido nacional-socialista, la industria, la administración y el ejército. ${ }^{15}$ Pero dentro de estos cuatro grupos también hubo una suerte de jerarquía implícita: fueron los grandes monopolios y el partido nazi quienes más se beneficiaron; los otros dos se conformaron con el mantenimiento del status quo. Este pacto, obviamente, se realizó a espaldas de la población alemana y es el que, durante el régimen nazi, propició las condiciones para su explotación laboral y su persecución política. Uno de los grupos que más se vieron perjudicados, pese a la propaganda y la supuesta defensa de un proletariado nacional por parte del nazismo, fueron los obreros, quienes perdieron la mayoría de las conquistas ganadas durante la República de Weimar.

El régimen nacional-socialista resultó ser completamente funcional, sostendrá Neumann, ${ }^{16}$ a las nuevas características del capitalismo: una concentración del capital económico en cárteles o conglomerados industriales $y$, por ende, una disolución de las relaciones de competencia que definían al libre mercado. Se trata, a fin de cuentas, del paso del capitalismo competitivo al capitalismo monopólico. Ahora bien, cabe preguntarse, ¿por qué el nacional-socialismo es funcional al desarrollo del capitalismo monopólico? Porque éste requiere de un poder totalitario o, como se denomina en el

\footnotetext{
13 Ibidem, p. 11.

${ }^{14}$ Hayes, Peter, "Introduction", en Neumann, Franz, Behemoth. The structure and practice of National Socialism, 1933-1945, Chicago, Ivan R. Dee, 2009, p. viii.

15 Neumann, F., Behemoth, p. 401.

${ }^{16}$ Ibidem, p 394.
} 
Behemoth, de una "economía de mando". ${ }^{17}$ Dicho en otras palabras: se requiere de una serie de disposiciones políticas, policíacas y legales que no sólo permita la constitución de monopolios, sino que a la postre los favorezca y fortalezca. Un ejemplo claro de esto -aquí nos limitamos a mencionarlo- fueron las leyes de cartelización obligatoria -fusión forzada de las pequeñas empresas con las grandes- y de arianización -expropiación de las empresas pertenecientes a judíos-. El nacional-socialismo convirtió en realidad el sueño de los industriales y los monopolistas. No sólo destruyó las instituciones y disposiciones jurídicas que ponían un coto a la cartelización de la economía, sino que fue mucho más lejos. Puso a su entera disposición el aparato coercitivo del Estado - a los monopolios industriales se les suma el monopolio de la fuerza física- para aterrorizar a la población y para reprimir todo tipo de expresión de descontento por parte de ella.

Neumann rechazó las explicaciones que ponían el acento en la creciente planificación política de la economía y en el supuesto advenimiento de un "capitalismo de Estado".18 Por el contrario, lo que se instaló en

${ }^{17}$ Ibidem, p. 295.

${ }^{18}$ Nos limitamos a señalar que aquí se enmarca la clásica discusión con F. Pollock y con quienes, dentro del Instituto, defendieron sus tesis (principalmente, Horkheimer). La postura de Pollock puede encontrarse en dos artículos publicados en la revista del Instituto: "State Capitalism: Its posibilities and limitations" y en "Is National Socialism a new order?". En este último puede verse claramente la diferencia con Neumann. Refiriéndose al nacional-socialismo, Pollock afirma que "el reconocimiento de una esfera económica dentro de la cual el Estado no debe y no puede intervenir, tan esencial en la era del capitalismo privado, es radicalmente repudiado. Como consecuencia, la ejecución del programa es impuesto por el poder estatal y nada esencial es librado al funcionamiento de las leyes del mercado u otras "leyes" económicas. La primacía de la política sobre lo económico, tan disputada bajo la democracia, está claramente establecida" (Pollock, Friedrich, "Is National Socialism a New Order?" en Studies in Philosopby and Social Science, IX, 1941, p. 453, la traducción y las cursivas son nuestras). Para una breve reseña de la discusión, véase José Sazbón, "El legado teórico de la Escuela de Frankfurt”, en Atilio Borón y Álvaro de Vita (comps.), Teoría y Filosofía Política, la recuperación de los clásicos en el debate latinoamericano, Buenos Aires, CLACSO, pp. 184-185. Una reconstrucción más detallada puede encontrarse en el capítulo 4 del libro de Moishe Postone, Marx Reloaded. Repensar la teoría crítica del capitalismo, edición y notas de A. Riesco Sanz y J. García López, Madrid, Traficantes 
Alemania era un "capitalismo monopolista totalitario"19 caracterizado por una economía fuertemente monopólica y una economía de mando. Lejos de ser la esfera política la que fija las directrices, en este esquema y en consonancia con la tesis central del Behemoth de que el nacional-socialismo tiende a negar al Estado, es quien las sigue. ${ }^{20}$ Lo interesante de esta explicación es que contribuye a desenmascarar algunos prejuicios respecto al nazismo y a su afán imperialista. En el libro de Neumann quedan al descubierto los motivos centrales de la campaña bélica de Alemania: más que lograr una supremacía aria a escala mundial, se trataba de poner la maquinaria industrial al máximo de su productividad y, por ende, extraer la mayor ganancia posible. ${ }^{21} \mathrm{Nada}$ mejor para lograr este propósito que una guerra a gran escala.

Las relaciones de dominación durante el nacional-socialismo fueron en gran medida unilaterales y se caracterizaron por la violencia física y el terror. ${ }^{22}$ Lo agentes más visibles al respecto fueron la policía, la Gestapo y las SS (que operaban como grupos paramilitares y que tenían facultad para aplicar la pena capital sin ninguna autorización previa). Pero, en realidad, estas relaciones de dominación eran la expresión de una destrucción sistemática (y hasta podría decirse premeditada) de la racionalidad inherente a las distintas instituciones del Estado y de la sociedad en su conjunto. ${ }^{23}$ Se instaló un funcionamiento

de Sueños, 2007, y en el artículo de Giacomo Marramao "Political Economy and Critical Theory", Telos, 20/24, 1975, pp. 56-80.

${ }^{19}$ Neumann, F., Behemoth, p. 295.

20 En artículos posteriores, Neumann matiza esta afirmación. Sostiene que "es indiscutible que el partido nazi ascendió al poder con la ayuda financiera y política de los dirigentes de las grandes empresas alemanas, quienes tenían sin duda la esperanza de utilizarlo para promover sus propios intereses. Pero el partido, una vez logrado el poder político, se emancipó de los hombres de negocios y su propio poder político se hizo autónomo. Fue entonces más lejos e intentó obtener posiciones dentro del poder económico" (Neumann, F., El Estado democrático y el Estado autoritario, Buenos Aires, Paidós, 1968, p. 25).

21 Wright Mills, Charles, "The Nazi Behemoth", en Power, Politics and People: The Collected Essays of C. Wright Mills, editado por Irving Louis Horowitz, Oxford, Oxford University Press, 1967, pp. 174 y 175.

22 Neumann, F., Behemoth, p. 446.

${ }^{23}$ La temática de la racionalidad / irracionalidad marca un contraste significativo entre Neumann, por un lado, y Adorno y Horkheimer, por el otro. En el Behemoth, la 
irracional de la burocracia, ${ }^{24}$ se destruyeron los límites entre los poderes ejecutivo, legislativo y judicial concentrándose cada vez más en la figura del Fübrer, ${ }^{25}$ se abolió la figura del contrato de trabajo, ${ }^{26}$ se perdieron las conquistas y la tradición de la lucha sindical, ${ }^{27}$ etc. Incluso la justificación teórica de las acciones del nacional-socialismo se tornó, a simple vista, errática y caprichosa: se pasaba de una perspectiva social, política, legal, etc., a otra en función de las conveniencias y los intereses del momento. ${ }^{28}$ Decimos "a simple vista" porque estas disposiciones, dirigidas a destruir todo vestigio de racionalidad, tenían paradójicamente una razón de ser: calibrar y mejorar la

dominación social se vincula más a una destrucción de la racionalidad, que a una suerte de racionalidad instrumental. Lo que no significa que, para el autor, las medidas tomadas por el nacional-socialismo no siguieran un plan estrictamente racional; efectivamente, cada palabra, cada disposición jurídica, cada decisión política y teórica estaba cuidadosamente pensada para maximizar la manipulación y el engaño de las masas. Pero de ello no se infiere la primacía de un pensamiento identitario o instrumental. De todas maneras, y en esto conviene matizar, esta tesis presente en el libro de Adorno y Horkheimer Dialéctica de la Ilustración -publicado dos años después que el Behemoth-, a saber, que la dominación se asocia a una pensamiento instrumental e identitario, asume un carácter más bien aporético y hay quienes sostienen -con buenos argumentos- que aun en este libro sombrío y "catastrófico" se conserva de manera implícita un concepto positivo de razón. A su vez, en la investigación de Neumann, no hay nada parecido a una defensa de la modernidad y la racionalidad incluso a la hora de analizar la necesaria generalidad del derecho no deja de advertir su sesgo ideológico-. Más bien se limita a hacer visibles los riesgos que comporta su destrucción en el contexto histórico específico del totalitarismo alemán. Marcando, con ello, otro hilo de continuidad con los postulados de la Teoría Crítica, a saber: el de no nombrar ni dar imágenes de lo positivo. Además, es menester señalar que en su libro no hay nada parecido a una teoría de la razón, ni siquiera la intención de desarrollarla. Con estas afirmaciones tomamos cierta distancia del artículo de Clara Serrano García y Carlos Fernández Liria, "Capitalismo e Ilustración. La intervención de Franz Neumann en la Escuela de Frankfurt", Arxius de sociología, 22, 2010, pp. $47-$ 60 , en el que se subraya, a nuestro juicio excesivamente, la diferencia entre Horkheimer, Adorno y Neumann.

${ }^{24}$ Neumann, F., Behemoth, p. 102.

${ }^{25}$ Ibidem, p. 497.

${ }^{26}$ Ibidem, p. 466.

27 Ibidem, p. 457.

${ }^{28}$ Ibidem, p. 510. 
maquinaria de terror necesaria para mantener el crecimiento sostenido de la economía y aterrorizar a la comunidad. ${ }^{29}$ Uno de los aspectos en donde esta imbricación de irracionalidad y dominación se vuelve más explícita es, como veremos a continuación, en el ámbito del derecho.

\section{E1 derecho, arcanum dominationis}

El pensamiento jurídico nazi se autodenominó "teoría de la institución". ${ }^{30}$ Suponía a la vez una apropiación y una neutralización de la crítica ideológica que el marxismo realizó contra el derecho formal. Es decir, la teoría de la institución parte del hecho de que la igualdad formal de la ley tiene un carácter encubridor de las relaciones sociales asimétricas y antagónicas. Tomando esta crítica como punto de partida, reemplaza una serie de figuras legales -como ser: la personalidad jurídica, la empresa, el propietario, el contrato de trabajo, y hasta la idea misma de Estado- por la noción de "institución". Esta alude a una suerte de organismo vivo; un organismo que se integra, a su vez, en una totalidad mayor: la comunidad del pueblo. ${ }^{31} \mathrm{Si}$ las empresas privadas son consideradas instituciones de la comunidad, entonces se desdibujan lo que antes eran las relaciones entre patrón y empleados, la idea misma de propiedad, de salario, etc. No obstante, esto no resuelve los antagonismos de clase -no hay nada parecido a la revisión de la idea de propiedad privada-. Es, en todo caso, una nueva forma de encubrirlos. Los antagonismos, según Neumann, subsisten y se agudizan en la economía monopolista. Dicho en otros términos, la teoría institucionalista del nazismo es la nueva fachada jurídica que necesita el capitalismo monopolista totalitario para expandirse a sus anchas. ${ }^{32}$

\footnotetext{
${ }^{29}$ Ibidem, p. 513.

${ }^{30}$ Neumann, F., Behemoth, p. 493. Las explicaciones relativas a la ley y teoría jurídica nacional-socialista son retomadas y ampliadas en el importante artículo "El cambio en la función de la ley en la sociedad moderna”, en Neumann, F., El Estado democrático y el Estado autoritario, pp. 30-69.

31 Neumann, F., Behemoth, p. 494.

32 Ibidem, p. 495.
} 
El teórico crítico acepta que el carácter general de la ley tiene una función ideológica. Pero, al negar la generalidad, como hizo el nacionalsocialismo, no se supera esta función. Es más, se eliminan las pocas barreras legales que limitaban el avance de los dueños de los medios de producción sobre el derecho de los trabajadores. Aun cuando el derecho formal brindaba una cierta previsibilidad al capitalismo competitivo y a su vez encubría las condiciones de desigualdad material, también garantizaba un mínimo indispensable de libertad individual. ${ }^{33}$ Esta garantía no debe considerarse menos importante que la función económica e ideológica (he aquí la falacia de la crítica marxista) y cuando se pierde, la política totalitaria que requieren los monopolios se abre paso sin dificultades.

¿De qué manera se destruye la generalidad y la racionalidad de la ley? A través de lo que se denominó patrones de conducta jurídica [Generalklauseln]. ${ }^{34}$ Una ley general siempre debe tener un mínimo de contenido concreto o una forma de aplicación a casos particulares para no quedar en la mera abstracción. Los Generalklauseln son una respuesta a esta necesidad que, en última instancia, termina por sacrificar la generalidad. ¿En qué consisten específicamente? Ellos introducen cláusulas que apelan, por ejemplo, al "sano sentir del pueblo" o a las "buenas costumbres" o a una moralidad supuestamente compartida. Esta apelación permite encontrar criterios para dirimir problemas o llegar a decisiones judiciales. El problema central es que no hay definición unívoca compartida por todos de lo que serían las buenas costumbres o el sano sentir del pueblo. Por el contrario, no sólo es difícil extraer criterios claros y unívocos de estas apelaciones, sino que en cada sociedad hay una multiplicidad de idiosincrasias y moralidades muchas veces contrapuestas y en tensión unas con otras.

El efecto que los Generalklauseln tiene sobre la generalidad de la ley es claro: (a) desdibuja los límites entre moralidad y legalidad -Kirchheimer también analiza la cuestión en su artículo sobre la ley penal en el nacionalsocialismo ${ }^{35}$-; (b) permite la introducción de medidas individuales -con lo cual se genera un sinnúmero de excepciones, privilegios y desequilibrios en la

\footnotetext{
${ }^{33}$ Ibidem, p. 497.

34 Ibidem, p. 487.

${ }^{35}$ Kirchheimer, Otto, "Criminal Law in National-Socialist Germany", en Studies in Philosophy and Social Science, Vol. VIII, 1939, pp. 446-448.
} 
aplicación de la ley-; (c) al ser el Fübrer la fuente de legitimidad y legalidad, se abre paso a un uso discrecional y político de la ley. Estos efectos no son casuales ni el resultado azaroso de una política sin rumbo fijo. Por el contrario, sirven para que las leyes se conviertan en medios para infundir terror y confusión en la población. La destrucción de la generalidad de la ley -o, como bien lo sintetiza Scheuerman, "la muerte de la ley racional" 36 - se ve con claridad en que:

(a) Se pasa por encima de la prohibición de retroactividad que está en la base del derecho ${ }^{37}$. Pierde vigencia el principio según el cual nulla poena sine lege, nullum crimen sine lege. El sistema nacional socialista permite castigar un acto que en el pasado no era considerado crimen porque no existía ley alguna que lo prohibiera.

(b) Se atenta contra la independencia del juez. ${ }^{38}$ De hecho, se pierden los límites que separaban al poder judicial del legislativo y el ejecutivo. Hay una injerencia directa del Fübrer sobre la justicia y el juez termina por cumplir funciones policiales. Kichheimer habla de la "transformación del juez de agente independiente de la sociedad en un órgano técnico de la administración";39 en otro artículo sostiene que "el interés de la gente de la corte es simplemente eliminar a los enemigos políticos". 40

(c) En el predominio, a nivel judicial, de lo que se denomina "Escuela libre" 41 o "Escuela de Kiel", ${ }^{42}$ la cual encuentra su fundamentación filosófica en la fenomenología y permite que el juez resuelva un caso y justifique sus decisiones en virtud de su "intuición" individual.

\footnotetext{
36 Scheuerman, W., Between the norm and the exception, p. 133.

37 Neumann, F., Behemoth, p. 500; Kirchheimer, O., "Criminal Law in NationalSocialist Germany", p. 446.

${ }^{38}$ Neumann, F., Behemoth, p. 500; Kirchheimer, O., "State Structure and Law in the Third Reich", en Scheuerman W. (ed.), The rule of law under siege. Selected essays of Franz. Neumann y Otto Kirchheimer, Los Angeles, California University Press, 1996, p. 144.

${ }^{39}$ Kirchheimer, O., "Criminal Law in National-Socialist Germany", p. 462.

${ }^{40}$ Kirchheimer, O., "State Structure and Law in the Third Reich", p. 154.

41 Neumann, F., Behemoth, p. 499.

42 Kirchheimer, O., "Criminal Law in National-Socialist Germany”, p. 445.
} 
(d) El crecimiento exponencial de la autoridad de los grupos paramilitares (especialmente las S.S.), a punto tal que ya no había instancia o institución externa que controle su accionar. En el caso de las S.S., se trataba de un grupo paramilitar librado a actuar como mejor les parezca. De hecho, les estaba autorizado aplicar la pena capital de forma discrecional. 43

(e) El derecho penal se convirtió en un medio de dominación. ${ }^{44} \mathrm{La}$ vaguedad con la que se definían los delitos -incluso escuchar música extranjera podía llegar a serlo-, la amplitud del significado del "delito político" y la aplicación indiscriminada de la pena capital, eran instrumentos eficaces para generar una adhesión y una sumisión irrestricta al régimen -también Kirchheimer analizó la ampliación en el contenido del derecho penal ${ }^{45} \mathrm{y}$ el uso extendido de la pena de muerte ${ }^{46}-$.

En fin, todo el sistema jurídico se convirtió en un arcanum dominationis. ${ }^{47}$ En un medio para aterrorizar a la población y para que la explotación laboral

43 Neumann, F., Behemoth, p. 501; Kirchheimer, O., "State Structure and Law in the Third Reich", p. 153.

44 Neumann, F., Behemoth, p. 499.

${ }^{45}$ Kirchheimer, O., "Criminal Law in National-Socialist Germany", p. 447.

${ }^{46}$ Kirchheimer, O., "State Structure and Law in the Third Reich", pp. 149 y 155.

47 Neumann, F., Behemoth, p. 493. En su libro La dictadura, Carl Schmitt afirma retomando las categorías de Arnold Clapmar- que la expresión arcana dominationis remite a los secretos de Estado. Según Schmitt, se trata de "los medios y consejos más internos y secretos que poseen los que ejercen el dominio en el Estado y que sirven por un lado al mantenimiento de la tranquilidad en el mismo y por otro a la conservación del estado existente de la República o del bienestar público". El autor establece una distinción entre arcana imperii y arcana dominationis. Los primeros están "referidos al Estado, a la situación del poder existente de hecho en los tiempos normales, y entre ellos se puede aludir a los distintos métodos empleados para mantener tranquilo al pueblo". Los arcana dominationis se hallarían al servicio de la conservación del poder de los príncipes o de la protección y defensa de las personas que ejercen la dominación durante acontecimientos extraordinarios (rebeliones, revoluciones), y aparecen asociados con situaciones de excepción. Es decir, los arcana dominationis de los que habla Neumann no son más que los consejos y disposiciones que toman quienes ocupan el poder en situaciones excepcionales, donde entra en 
a la que era sometida no encontrara resistencia alguna. La pregunta que se hace Neumann es si esto, efectivamente, merece llamarse "derecho" y responde: "Si el derecho no es más que la voluntad del soberano, sí; pero si el derecho, a diferencia del mandato del soberano, ha de ser racional en su forma o en su contenido, no. El sistema jurídico nacional-socialista no es sino una técnica de manipulación de las masas por el terror". 48

\section{3. ¿Dominación bilateral?}

Hemos visto, hasta aquí, algunas de las características que Neumann le atribuye a la dominación. El nacional-socialismo hizo un uso desproporcionado de la propaganda ideológica -apropiándose de muchas de las reivindicaciones del marxismo, pero desvirtuándolas por completo- $\mathrm{y}$, sobre todo, de la violencia y el terror para atemorizar y atomizar a la población. Pero este uso desproporcionado sólo fue posible, según el autor, porque primero se destruyeron todas las mediaciones legales e institucionales. En una palabra: porque la destrucción del Estado y del contenido racional de la ley, permitió una coacción sin mediaciones de la clase dirigente sobre la dirigida. Ante esto, es necesario preguntar: ¿puede, entonces, hablarse de dominación bilateral en el Behemoth?

Aclaremos, primero, a qué hace referencia el concepto de dominación bilateral. Los individuos y/o grupos sociales son comprendidos -a partir de este concepto- como co-partícipes del ejercicio de la dominación, en tanto y en cuanto le brindan una base consensual -negociada y renegociada constantemente- para legitimarla. En palabras de Axel Honneth:

(...) no es la obediencia producida directa o indirectamente, sino el horizonte de las orientaciones normativas de los grupos sometidos el que asienta las bases que sostienen la dominación social por grupos privilegiados. Se trata, pues, de una relación bilateral de dominio social: las supuestas evidencias culturales y las orientaciones valorativas conducentes

plena vigencia la "razón de Estado". Cfr. Schmitt, Carl, La dictadura, Madrid, Revista de Occidente, 1968, pp. 45-47.

${ }^{48} \mathrm{Ibidem}$, p. 504, las cursivas son nuestras. 
a la acción, a través de cuyo filtro todos los grupos sociales se perciben como una estructura institucional establecida, confluyen en un consenso fragmentario, pero, sin embargo, efectivo, que es capaz de asegurar un grado suficiente de reconocimiento normativo dentro de una situación de desigualdad institucionalizada en la distribución de los bienes sociales. ${ }^{49}$

De la cita y de los cuestionamientos que Honneth le hace al legado de la Teoría Crítica -sobre todo a Horkheimer, Adorno y Habermas- en su libro Crítica del poder, podemos ampliar algunas precisiones sobre el concepto en cuestión. Primero, que presupone la participación activa de los individuos y/o grupos sociales no sólo en el orden socio-político en general, sino también en las prácticas de dominación que los someten. Los sujetos no son víctimas pasivas, sino que se involucran en aquellas prácticas que los perjudican y depositan en ellas su energía e incluso sus deseos y aspiraciones. Segundo, que las instancias y prácticas de dominación no están exentas de una conflictividad que, cuando no se expresa abiertamente, permanece latente bajo la forma de un frágil consenso moral o una aceptación pragmática. Por último, que los acuerdos tácitos o contratos sociales implícitos, ${ }^{50}$ muchas veces, legitiman relaciones sociales asimétricas, cuando no abiertamente injustas y desiguales. Esto no debe interpretarse en el sentido de que los acuerdos, al no estar

\footnotetext{
${ }^{49}$ Honneth, A., Critica del poder, p. 101, las cursivas son nuestras.

50 Honneth toma la idea de "contrato social implícito" del libro La injusticia del historiador Barrington Moore. Según este autor, "las personas que viven en cualquier sociedad deben resolver los problemas de autoridad, de división del trabajo y de distribución de bienes y servicios. Esto lo lograrán en parte poniendo en práctica principios rudos, pero eficaces, de desigualdad social, y enseñando a los otros, con mayor o menor éxito, a aceptar y obedecer dichos principios. Éstos crean sobre la marcha un contrato social implícito y algunas veces explícito. $\mathrm{Y}$ hay muchas formas de lograrlo. El miedo, la fuerza y el fraude no son la base de ninguna sociedad humana, aun cuando su papel ha sido decisivo (...), ni tampoco por eso son las sociedades solamente sistemas más elaborados de intercambios, sino que son una mezcla de cohesión e intercambio" (Barrington Moore, La injusticia. Bases sociales de la obediencia y la rebelión, México, UNAM / Instituto de investigaciones sociales, 1989, pp. 23 y 24).
} 
verbalizados, resultan inmodificables o cerrados, sino que precisamente están en una permanente negociación conflictiva. ${ }^{51}$

Volviendo a la pregunta que formulamos líneas arriba, en principio todo indica que en el Behemoth de Neumann no podría identificarse un concepto de estas características. De hecho, la falta de mediaciones vuelve más unilateral el ejercicio de la dominación. Pero esta primera respuesta es, cuanto menos, apresurada. Sobre todo si se tiene en cuenta que el nacionalsocialismo, según Neumann, constituyó una suerte de no-Estado. Es decir, una negación del orden político y social. Sólo por eso pudo llevar la dominación a su máxima unilateralidad. Dicho de otra manera, se trata de una situación histórica relativamente excepcional. Todo orden socio-político que se erija como tal -aun el más antidemocrático y absolutista- requiere de compromisos y alianzas más o menos generalizables para conservar un mínimo de cohesión y estabilidad. En palabras del autor:

En una monarquía absoluta, en un sistema constitucional y en una democracia, los compromisos entre las pretensiones de los diversos grupos tienen validez universal. Si el estado se ve en la necesidad de coordinar e integrar cientos y miles de individuos y grupos en pugna, el proceso se ha de realizar de un modo que tenga fuerza obligatoria universal, es decir, mediante el derecho racional abstracto o por lo menos a través de una burocracia que actúa racionalmente..$^{52}$

Como hemos visto, el nacional-socialismo logró estos compromisos con otros tres sectores. Pero, en realidad, el antagonismo y la rivalidad entre las élites de poder político-económico nunca desapareció. En todo momento estuvo presente la amenaza de que uno de ellos "devorara" a los otros y esto los mantuvo alertas, en actitud de desconfianza mutua. Además, claro está, del hecho de que era un compromiso realizado a espaldas del resto de la población. De modo que

${ }^{51}$ Para un desarrollo más exhaustivo de este concepto, véase el trabajo de nuestra autoría: Abril, Francisco, "Repensar la dominación. Axel Honneth y el legado de la Teoría Crítica", Revista Mexicana de Ciencias Políticas y Sociales, 63, 232, 2018.

${ }^{52}$ Neumann, F., Behemoth, p. 517. 
[e]n el nacional-socialismo toda la sociedad está organizada en cuatro grupos fuertes y centralizados, cada uno de los cuales actúa bajo el principio del liderazgo, cada uno con poderes legislativos, administrativos y judiciales propios. No hace falta un derecho universal ni una burocracia que actúe racionalmente para que haya integración. No es preciso que los compromisos entre los cuatro organismos se expresen en un documento legal ni han de estar institucionalizados (como los "acuerdos entre caballeros" de las industrias monopólicas). (...) No hace falta que haya un estado que se encuentre por encima de todos los grupos. El estado puede hasta ser un estorbo para los compromisos y para la dominación sobre la clase gobernada. ${ }^{5}$

Entonces, hay acuerdos implícitos o informales -esos "acuerdos entre caballeros" que se mencionan, no sin ironía, en la cita-, pero "excluyentes" dejan afuera a amplios sectores sociales- y la integración social sólo es posible en virtud del uso de la violencia y la manipulación de las masas.

Teniendo en cuenta la relevancia que Neumann le atribuye a los "compromisos", la respuesta a la pregunta formulada líneas arriba deviene claramente insuficiente. La dominación nacional-socialista sólo pudo volverse unilateral en la medida en que presupuso la destrucción del ordenamiento político y jurídico. Si tal ordenamiento se mantiene -aun cuando la racionalidad de sus instituciones se reduzca al mínimo-, requerirá de ciertos compromisos o contratos explícitos o implícitos con diferentes sectores de la población para mantener una relativa estabilidad. ${ }^{54}$ En este sentido, en los

\section{Ibidem.}

${ }^{54}$ De hecho, esto es lo que caracterizó (con sus limitaciones) a la República de Weimar. En el primer capítulo del Behemoth, Neumann analiza brevemente este momento histórico y los factores que intervinieron en la transición al totalitarismo. La elaboración de la Constitución de Weimar, expresó, sí, una serie de pactos elaborados entre diversos sectores de la sociedad alemana. En ese período se incorporaron muchas de las demandas realizadas por la clase obrera durante la revolución del '18. Asimismo, gran parte del capital político de la social-democracia residía en su cercanía y afinidad con algunos sindicatos y grupos de trabajadores. Es decir, su (precaria) gobernabilidad se debió, entre otras cosas, al pacto con estos 
regímenes políticos, por diversos que sean, el ejercicio de la dominación requiere de una cierta bilateralidad. Sólo en la medida en que el nacionalsocialismo tendió a negar y destruir el orden socio-político, pudo maximizar el uso de la violencia, el terror y la propaganda burda. ${ }^{55}$

Es precisamente la noción de "compromiso" la que representa, para Axel Honneth, una de las principales ventajas teóricas del planteo de Neumann. A partir de ella se proyecta una imagen de los procesos de integración social totalmente distinta a la que predominó en círculo interno de la Teoría Crítica. En los análisis históricos y teóricos de Neumann la integración no se definió como un "circuito cerrado de ejercicio centralizado

sectores de la sociedad. Ahora bien, estos pactos fueron de por sí insuficientes y los antagonismos no sólo persistieron, sino que se agudizaron. Entraron en juego múltiples factores que debilitaron cada vez más a la democracia: los efectos del tratado de Versalles, la indecisión y tolerancia pasiva de la social-democracia respecto a los grupos de extrema derecha, la presión permanente de y las concesiones realizadas a los grandes cárteles, la fragmentación de la clase obrera y la oposición sin miramientos del Partido Comunista, fueron sólo algunos de ellos.

${ }^{55}$ En un excelente artículo sobre la posibilidad de fundar una filosofía política a partir de los estudios clásicos de la Teoría Crítica, Miguel Abensour destaca la importancia de la tesis central del Behemoth de que el nazismo y el totalitarismo constituyen formas de no-política. Esta tesis permite diferenciaciones necesarias (entre totalitarismo, absolutismo y democracia; entre dominación y poder político, etc.) que, a diferencia de otros miembros del Institut, resguardaron a Neumann de los posicionamientos "catastrofistas" centrados, de manera exclusiva, en la crítica de la dominación. En palabras de Abensour: "la articulación entre la crítica de la dominación y el pensamiento de la política es concebible porque democracia o república están permanentemente expuestas a su corrupción, es decir a degenerar en Estado autoritario [el absolutismo podría ser una de sus versiones, F.A.], noción esta que no debe confundirse con la de Estado totalitario o totalitarismo. Es precisamente lo que un teórico crítico, F. Neumann, tuvo el mérito de volver posible; su pensamiento se ordena, en efecto, alrededor de tres polos: el Estado democrático, el Estado autoritario, y el Estado totalitario o totalitarismo (...) el Estado totalitario tiene como particularidad ser un no-Estado, en la medida en que la dominación se ejerce sin recurrir a las reglas del derecho, en un Estado de no-derecho. Habría dominación directa de los grupos dominantes sobre el resto de la población (...)" (Abensour, Miguel, "¿Por una filosofía política crítica?" en AA.VV, Voces de la filosofía francesa contemporánea, p. 67). 
de la dominación, control cultural y conformidad individual", ${ }^{56}$ sino como el resultado de un proceso conflictivo de acuerdo entre los grupos sociales. ${ }^{57} \mathrm{Un}$ "proceso global de comunicación" 58 en el que los grupos negocian unos con otros en virtud del poder relativo que cada uno detenta y es a partir de esta negociación que se cristalizan, siquiera de forma momentánea y precaria, las instituciones sociales. Es decir, no hay mera imposición o violencia, sino que se atiende al complejo "fenómeno de la legitimidad política". ${ }^{59}$ Es a partir de ella que "el orden constitucional de una sociedad es siempre la expresión de un compromiso generalizable o consenso entre fuerzas políticas". ${ }^{60}$

Esta afirmación trae aparejada una de las principales características atribuidas al concepto de dominación bilateral: la "participación" de los grupos sociales. Así, "lo que configura el elemento social a partir del que se constituye el proceso de integración social son las perspectivas de acción especificas del grupo, no los motivos instintivos producidos por el sistema". ${ }^{61}$ Esta observación de Honneth corresponde fielmente a lo expuesto en el Behemoth. Neumann analiza el margen de acción de diferentes actores sociales, por ejemplo, los ingenieros, los soldados o los obreros especializados. En todos estos casos, se trata de grupos que permanecen expectantes -advierten las contradicciones y las promesas incumplidas por el nazismo- y con una cierta predisposición a actuar llegado el caso. No hay nada parecido a víctimas pasivas ni acríticas. Incluso se le atribuye a la masa, a la población más

\footnotetext{
${ }^{56}$ Honneth, A., "Teoría Crítica”, p. 456.

57 William Scheuerman coincide en esto con Honneth. Según Scheuerman, la esfera política (donde las visiones sociales rivales entran en conflicto y la definición y regulación misma de los mecanismos sistémicos de dominación es materia de disputa) recibió escasa atención por parte del círculo interno de la Teoría Crítica. En su lugar, y a diferencia de Neumann, enfatizaron y sobredimensionaron la capacidad de integración del capitalismo de Estado. Para ellos la "sociedad totalmente integrada" no deja espacio al conflicto o intercambio político genuino y, por lo tanto, la teoría debe centrar exclusivamente su atención en "la experiencia de integración total". (Scheuerman, W., Between the norm and the exception, p. 153).

58 Honneth, A., "Teoría Crítica”, p. 466.

${ }^{59}$ Ibidem, p. 465.

60 Ibidem, p. 465.

${ }^{61}$ Ibidem, p. 466, las cursivas son nuestras.
} 
perjudicada y golpeada por el nacional-socialismo, una tradición crítica que podría impulsarlas a actuar. Dice Neumann:

Las promesas del régimen a las masas son agradables, pero se han roto muchas de ellas y se han sacrificado todos los puntos esenciales del programa del partido. Las masas han de notar este antagonismo, pues no son criaturas inocentes, sino que tienen tras de sí una larga tradición, una tradición que les inculcó un espíritu crítico y les hizo darse cuenta de que el hecho esencial de la civilización moderna es precisamente ese antagonismo entre una economía que pueda producir con abundancia para el bienestar, pero que sólo produce para la destrucción. ${ }^{62}$

Es justamente en relación con este carácter participativo de los diferentes grupos, que debe analizarse el poder mismo del Estado en tanto institución. De hecho, la dominación estatal -entiéndase: no la del Behemoth-siempre parte de un "entretejimiento" de los potenciales de poder de los respectivos grupos sociales ${ }^{63}$.

Recapitulemos: la investigación de Neumann muestra que la dominación nacional-socialista tuvo un carácter unilateral sólo en la medida en que previamente destruyó las instituciones y la racionalidad propia de un orden político. En caso de que, por el contrario, estas instituciones se conserven, el ejercicio del poder supone la capacidad para tejer alianzas y entablar "compromisos" entre diversos sectores que garanticen un mínimo de cohesión y estabilidad social. Por lo tanto, podría decirse que, en términos generales, el análisis del poder político y la dominación debe tener en cuenta la participación de los distintos actores socio-políticos, el carácter conflictivo de sus relaciones y su capacidad para llegar a compromisos. Es decir, encontramos aquí, al menos allí donde se conservan las instituciones políticas y jurídicas, las tres precisiones que mencionamos antes respecto al concepto de dominación bilateral.

62 Neumann, F., Behemoth, p. 512.

${ }^{63}$ Honneth, A., "Teoría Crítica", p. 467. 
Excurso. Hay que mencionar, pese a encontrar en la propuesta de Neumann las coordenadas necesarias para repensar la dominación, una limitación importante. El autor desestima o, mejor, subestima la posibilidad de que parte de la población alemana haya consentido las políticas del nacionalsocialismo. Es decir, no tiene en cuenta la posibilidad de que haya habido un contrato social implícito entre la población alemana y el régimen nacionalsocialista, por mínimo que este contrato haya sido. Si bien Neumann no tuvo en cuenta este "consentimiento", sí prestó atención al fenómeno de la adhesión. En su artículo tardío "Angustia y política"64 [1954] postula la tesis socio-psicológica de una "identificación cesareana" 65 de las masas con el líder. La adoración e identificación con este último se debe, fundamentalmente, a que representa una figura que reduce la angustia y el miedo -aquí se sirve, literalmente, del concepto freudiano de Angst-con el que viven las masas bajo ciertas condiciones socio-históricas. A su vez, es el mismo régimen político basado en liderazgos autoritarios el que propicia, alimenta y se beneficia de esa angustia provocada en las masas. De todas maneras, resulta evidente que el término "adhesión" remite, en el marco de su artículo, a una suerte de manipulación psicológica y no a un acuerdo entre diferentes grupos -aunque podría dilucidarse en qué medida una cosa incide sobre la otra-. "Las identificaciones cesarianas", escribe Neumann, "pueden representar un papel en la historia cuando la situación de las masas corre un peligro objetivo, cuando éstas son incapaces de entender el proceso histórico y cuando la angustia activada por el peligro se convierte, a través de la manipulación, en angustia persecutoria neurótica". ${ }^{66}$ Así, su fecundidad para pensar un vínculo socio-histórico entre la dominación bilateral y el totalitarismo nazi queda, por lo menos, en entredicho.

Cabe mencionar que Honneth dedica una lectura a este artículo en dos oportunidades. La primera es una breve reseña publicada en el libro Schlïsseltexte der Kritischen Theorie [Textos claves de la Teoría Crítica]. ${ }^{67}$ El

\footnotetext{
64 Este artículo puede encontrarse en Neumann, F., El Estado democrático y el Estado autoritario, pp. 250-277.

65 Ibidem, p. 260.

${ }^{66}$ Ibidem, las cursivas son nuestras.

${ }^{67}$ Honneth, Axel (ed.), Schlusseltexte der Kritischen Theorie, Weisbaden, VS Verlag, 2006, pp. 152 y 155.
} 
segundo se titula "Angustia y política. Puntos fuertes y puntos débiles del diagnóstico de las patologías de Franz Neumann” y se publicó en su libro Patologías de la razón [2007]. En este último artículo busca actualizar la tesis socio-psicológica de Neumann, proponiendo una novedosa vinculación con la psicología "revisionista" de Erich Fromm -autor que también perteneció al círculo "externo"-. Lo que sugiere es que hubiera sido más productivo para Neumann basar su tesis no en la ortodoxia freudiana, sino "en las reflexiones procedentes de la teoría de la relación de objeto, representadas en el Instituto de Investigación Social en forma rudimentaria sólo por Erich Fromm". ${ }^{68}$ Este último proporciona una base teórica que, poniendo el acento en la interacción y en la intersubjetividad, explicaría de modo más fecundo - que partiendo de una lectura literal de Freud- el tema de los miedos y las angustias. De hecho, es interesante advertir la centralidad que tiene para Fromm, ya desde el título de su clásico libro El miedo a la libertad ${ }^{69}$ esta temática. Gran parte de su pensamiento está orientado a explicar el miedo, la angustia, el sentimiento de impotencia y soledad que acosa al hombre moderno y lo lleva a encontrar certeza y seguridad en figuras autoritarias o en un liso y llano conformismo. Lo que, por cierto, podría constituir un modo de brindar consentimiento y legitimidad a las relaciones intersubjetivas de dominación.

No es nuestra intención entrar aquí en detalles conceptuales, pero sí es menester subrayar el hecho de que Honneth, en su comentario al artículo de Neumann, vuelve a ensayar un vínculo entre los autores que se mantuvieron en la "periferia" del Institut y a plantear una posibilidad que nosotros consideramos de suma relevancia: la de reconstruir y actualizar el legado de la Teoría Crítica retomando el aporte de Neumann y Fromm ${ }^{70}$. Entendemos

${ }^{68}$ Honneth, Axel, Patologías de la razón. Historia y actualidad de la Teoría Crítica, Buenos Aires, Katz, 2009, pp. 165-166.

69 Véase la elogiosa reseña que Honneth le dedica a "Die Frucht vor der Freibeit" en Schlüsseltexte der Kritischen Theorie, pp. 152-155.

${ }^{70}$ Cabe mencionar que tanto Neumann como Fromm fueron autores centrales en el proyecto editorial de una de las figuras claves de la sociología argentina: Gino Germani. El sociólogo argentino no sólo publicó y prologó El miedo a la libertad además de usar las reflexiones de Fromm en varios de sus ensayos; sólo por mencionar uno que aquí nos resulta de particular interés: "La integración de las masas a la vida política y el totalitarismo"70-, sino la importante compilación de ensayos de Franz Neumann titulada El Estado democrático y el Estado autoritario. Consideramos que 
que la reconsideración de estas figuras periféricas y relativamente olvidadas en los estudios actuales sobre la Teoría Crítica de Frankfurt, constituye una línea abierta de investigación que sería productivo desarrollar y profundizar en futuros trabajos. ${ }^{71}$

\section{Consideraciones finales}

A lo largo del presente trabajo procuramos dilucidar el alcance y las limitaciones de la propuesta de Neumann para repensar la dominación. Hemos visto cómo el ejercicio de esta última es diferente, según el teórico crítico, en función de cada régimen político. Es menester que se construyan, en las democracias, en los absolutismos y en los totalitarismos, "compromisos" a partir de negociaciones conflictivas entre los grupos sociales. Lo que nos permitió, al menos en principio, identificar las tres características del concepto de dominación bilateral: la participación, el conflicto y el consentimiento.

Lo excepcional es que, según se desprende de nuestra lectura del Behemoth, en el caso del totalitarismo nazi estos compromisos se tejieron en base a los intereses de las élites de poder, sin tener en cuenta al resto de la población y haciendo uso excesivo de la propaganda, la fuerza y el terror. Una dominación que sólo fue posible porque previamente se destruyó la racionalidad del Estado y del derecho, racionalidad por medio de la cual es posible garantizar un mínimo de consentimiento y legitimidad a las instituciones socio-políticas.

esta coincidencia dista de ser meramente anecdótica y que, en todo caso, puede trabajarse una conexión sistemática entre estos autores, de cara a una revisión de la Teoría Crítica y de sus posibles contribuciones para pensar la historia y la actualidad de nuestro país. Remitimos al capítulo quinto del libro de Alejandro Blanco, Razón y modernidad. Gino Germani y la sociología en la Argentina, Buenos Aires, Siglo XXI, 2006, pp. 133-160.

${ }^{71}$ En el caso de Neumann, el artículo de Pablo López Álvarez sienta un antecedente notable de que esta tarea puede efectivamente emprenderse: "Bebemoth o la Ilustración devastada. Reconsiderando a Franz Neumann”, Daimon. Revista internacional de filosofía, Suplemento 3, 2010, pp. 207-214. 
Si bien los aportes de Franz Neumann representan una alternativa abierta en el horizonte de la Teoría Crítica y logra eludir ciertos reduccionismos en los que incurrieron los autores del círculo "interno" a la hora de tematizar la dominación, no logró en su libro del "42 analizar detalladamente la posibilidad de que el nacional-socialismo haya contado con un consentimiento -siquiera parcial y tamizado por el terror- por parte de la población. Pero esta dificultad en su enfoque -que, pese a sus esfuerzos posteriores, no pudo superar- señala, asimismo, una vía teórica promisoria y no transitada aún: la de poner en diálogo, de manera sistemática, al jurista y politólogo alemán con Erich Fromm y, en general, con los otros autores del círculo "externo". Esto daría lugar a actualizar el legado de la Teoría Crítica, sin dejar atrás su pasado.

\section{Referencias bibliográficas}

Abensour, Miguel, “¿Por una filosofía política crítica?” en AAVV, Voces de la filosofía francesa contemporánea, Buenos Aires, Colihue, 2005, pp. 23-69.

Abril, Francisco, "Repensar la dominación. Axel Honneth y el legado de la Teoría Crítica”, Revista Mexicana de Ciencias Políticas y Sociales, 63, 232, 2018.

Blanco, Alejandro, Razón y modernidad. Gino Germani y la sociología en la Argentina, Buenos Aires, Siglo XXI, 2006.

Darity, William (ed.), International Encyclopedia of the Social Science (2nd. Edition), The Gale Group, Detroit, 2008.

Hayes, Peter, "Introduction" en Neumann, Franz, Behemoth. The structure and practice of National Socialism, 1933-1945, Chicago, Ivan R. Dee, 2009.

Honneth, Axel, "Teoría Crítica", en Giddens, Anthony y Turner, Jonathan (comps.) La teoría social, hoy. Madrid, Alianza, 1990, pp. 445-488.

Honneth, Axel (ed.), Schlusseltexte der Kritischen Theorie, Weisbaden, VS Verlag, 2006.

Honneth, Axel, Crítica del poder, Madrid, Mínimo Tránsito, 2009. 
Honneth, Axel, Patologías de la razón. Historia y actualidad de la Teoría Crítica, trad. de Griselda Mársico, Katz, Buenos Aires, 2009.

Kätz, Barry, "The Criticism of Arms: The Frankfurt School Goes to War" en The Journal of Modern History, 59, 3, 1987, pp. 439-478.

Kirchheimer, Otto, "Criminal Law in National-Socialist Germany" en Studies in Philosophy and Social Science, VIII, 1939, pp. 444-463.

Kirchheimer, Otto, "State Structure and Law in the Third Reich", en Scheuerman W. (ed.), The rule of law under siege. Selected essays of Franz Neumann y Otto Kirchbeimer, Los Angeles, California Univ. Press, 1996, pp. 142-172.

Laudani, Raffaele (ed.), Secret Reports on Nazi Germany. The Frankfurt School Contribution to the War Effort, New Jersey, Princeton University Press, 2013.

López Álvarez, Pablo “Behemoth o la Ilustración devastada. Reconsiderando a Franz Neumann”, Daimon. Revista internacional de filosofía, Suplemento 3, 2010, pp. 207-214.

Marramao, Giacomo, "Political Economy and Critical Theory", Telos, 20/24, 1975, pp. 56-80.

Moore, Barrington, La injusticia. Bases sociales de la obediencia y la rebelión, México, UNAM / Instituto de investigaciones sociales, 1989.

Neumann, Franz, El Estado democrático y el Estado autoritario, Buenos Aires, Paidós, 1968.

Neumann, Franz, Behemoth. Pensamiento y acción en el nacional-socialismo, , México, FCE, 2005.

Pérez, Alberto, "La teoría crítica entre el centro y los márgenes del Instituto de Investigación Social”, Pensar, 2, 2007, s/p.

Pollock, Friedrich, "Is National Socialism a New Order?" en Studies in Philosophy and Social Science, IX, 1941, pp. 440-456.

Sazbón, José, "El legado teórico de la Escuela de Frankfurt", en Borón, A. y de Vita, A. (comps.), Teoría y Filosofía Política, la recuperación de los clásicos en el debate latinoamericano, Buenos Aires, CLACSO, 2002, pp. 184- 185. 
Scheuerman, William, Between the norm and the exception. The Frankfurt School and the rule of law, Cambridge, The MIT Press, 1994.

Serrano García, Clara y Fernández Liria, Carlos, "Capitalismo e Ilustración. La intervención de Franz Neumann en la Escuela de Frankfurt", Arxius de sociología, 22, 2010, pp. 47-60.

Postone, Moishe, Marx Reloaded. Repensar la teoría crítica del capitalismo, Madrid, Traficantes de sueños, 2007.

Schmitt, Carl, La dictadura, Madrid, Revista de Occidente, 1968.

Wiggershaus, Rolf, La Escuela de Francfort, Buenos Aires, FCE, 2010.

Wright Mills, Charles, "The Nazi Behemoth", en Power, Politics and People: The Collected Essays of C. Wright Mills, editado por Irving Louis Horowitz, Oxford, Oxford University Press, 1967, pp. 170-178.

Recibido: 02/2019; aceptado: 08/2019 